\title{
Experiences of LGBTQ-identifying students, interns and practitioners of dietetics
}

Shelly DeBiasse, PhD, RDN; Amy Branham, MS, RDN, LDN; Nicole McFarland, MS

\begin{abstract}
Lesbian, gay, bisexual, transgender and/or queer (LGBTQ) identified individuals comprise over five percent of the US population. It is unknown how many US dietetics students, interns, or practitioners identify as LGBTQ as these data are not collected. LGBTQ-identifying individuals, including those enrolled in healthcare professions education programs, experience higher rates of anxiety, depression, stigmatization, discrimination and isolation and incur unmet healthcare needs, but to date there have been few studies of these issues among LGBTQ-identified dietetics students/practitioners. The aim of this study was to characterize the experiences of LGBTQ-identified students, interns, and practitioners of dietetics and to assess for differences in experiences between $L G B T Q$ and non-LGBTQ identified participants relative to gender/sexual identity. Using a mixed-methods design grounded in Feminist Standpoint theory, we enrolled $n=10$ LGBTQ students, interns, and professionals for semi-structured interviews and $n=13$ I participants of all gender/sexual identities for a survey. Qualitative analyses identified experiences of participants with non-LGBTQ-identified individuals that negatively affected their education, internships, and practice: heteronormative assumptions/talk, misgendering, microaggressions, religious/age-related biases, and expectations to educate on LGBTQ-related issues. Also reported were frequent self-editing/lying/closeting. Quantitative analyses confirmed explicit bias against LGBTQ-identified individuals, and lack of awareness of LGBTQ issues by non-LGBTQ identified participants. LGBTQ-identified participants gave significantly greater import than non-LGBTQ identified participants to coursework/education related to nutrition assessment/care of LGBTQ-identified patients/clients. The Academy and ACEND must mandate education, training, and continuing education requirements on inclusion and content on nutrition/healthcare needs of LGBTQ-identifying patients/clients to achieve an inclusive profession competent to treat the entire US population.
\end{abstract}

\section{Introduction}

According to the Williams Institute (2020) at the UCLA School of Law, approximately 11.3 million people in the US identify as LGBT. A 2020 Gallup poll finds that 5.6\% of the American population identify as Lesbian, Gay, Bisexual, or Transgender (LGBT) (Gallup, 202I). Since its inception in 1917, the profession of dietetics and its professional association, the Academy of Nutrition and Dietetics (the Academy) has been comprised almost exclusively of cis-gender, heterosexual, white females. The Commission on Dietetics Registration (CDR) (2019), the credentialing agency for and "sister organization" of the Academy, reports that out of 89 , 303 registered dietitian nutritionists (RDN), 85.6\% identify as female, $3.8 \%$ identify as male, and $10.6 \%$ did not report their gender identity (CDR Registry Statistics, November 2019). For nutrition dietetics technician, registered (NDTRs), out of 3,539 NDTRs, $66.5 \%$ identify as female, $4.4 \%$ identify as male, and $29.1 \%$ are "not reported". This may reflect $10.6 \%$ or II,047 RDNs and $29.1 \%$ or 1,548 NDTRs identify as transgender, gender queer, agender or intersex, though these category options are not included in the reporting of gender on membership surveys. Sexual preference is 
not included in any data collected by the Academy or its sister organizations (Burt, et al. in press).

Disparities exist in LGBTQ-identifying individuals' healthcare including unmet medical needs, adverse health outcomes (Radix \& Maingi, 2018), and higher rates of anxiety (Kates et al., 2016), depression (Kates et al., 2016), stigmatization (Safer et al., 2016), discrimination (Safer et al., 2016), and isolation (Hsieh, 2014). This trend is also true of $L G B T Q$ identifying individuals studying and practicing in the health professions (Eliason et al., 2011; Przedworski et al., 2015; Robertson, 2017). Minority Stress Theory (MST) (Meyer, 2003), has been postulated as a framework to explain the disparity in physical and mental health challenges faced by LGBTQidentifying individuals. In brief, MST postulates that stigma, prejudice, and discrimination create a hostile and stressful social environment which in turn contributes to physical and psychological/emotional disorders. Meyer asserts that "the experience of prejudice events, expectations of rejection, hiding and concealing, internalized homophobia and ameliorative coping processes" are "stress processes" that contribute to greater physical and mental health challenges in individuals who identify as LGBTQ vs. heterosexual, cisgender identifying individuals (Meyer, 2003, p. 674). Alessi et al's. (2017) qualitative analyses exploring the first-year university experience of sexual minority students shows that their sample of $n=21$ indicated increased stressors beyond the typical university experience specific to their gender-identity and sexuality including stigma. Of interest, these participants manifested resilience in response to this stress through joining campus organizations, taking pride in their identities and other social and interpersonal supports.

Briefly, Feminist Standpoint theory challenges researchers to begin from the everyday lives of oppressed groups rather than the conceptual frameworks of the dominant social institutions and disciplines that provide researchers with the "resources needed for administration and management of the oppressed" (Harding 2006, p.48). There is evidence that oppression exists in dietetics spaces, though much of the work to date focuses upon oppression of racial/ethnic groups (Lund et al., 2021; White \& Brown, 202I; DeBiasse et al, 202I). To date and to our knowledge, there have been few studies designed to evaluate the social challenges reified by bias toward LGBTQ-identifying individuals within the professional dietetics rank and file, or that describe the lived experience of LGBTQ-identifying dietetics students, interns, or professionals as they navigate their academic programs, supervised practice, and professional lives. This study, informed by Feminist Standpoint theory, is designed to help fill this gap. The aim of our study was to characterize the lived experience of LGBTQ-identifying students, interns, and professionals in dietetics. Phase one of this research engaged individuals in dietetics who self-identify as LGBTQ in semi-structured interviews that were analyzed qualitatively to determine the content of questions that were included in the phase two survey of the study which included both LGBTQ and non-LGBTQ-identified participants.

\section{Methods}

\section{Theoretical foundation}

The study was guided by Feminist Standpoint theory. This epistemological approach uses "strong objectivity" (Harding, 2006 p. 5l.) to locate practices of power that appear in the "conceptual frameworks favored by dominant social institutions and the disciplines that service them" (Harding, 2006 p. 48.). To achieve this, Feminist Standpoint approaches begin from the everyday lives of oppressed groups rather than the conceptual frameworks of the dominant social institutions. In this way, researchers better come to understand the issues that most effect the oppressed groups that they seek to understand through the research process. This approach "studies up" (Harding, 2006 p. 5I.); conceptual frameworks for the research are derived from the lives of the oppressed, thereby extending the benefits of methodological control back to the beginning of the research project. The study was approved by the Boston University IRB (X5455).

\section{Study Design}

The study was a mixed methods design grounded in Feminist Standpoint theory. Qualitative data from the semi-structured interviews were collected during phase one of the study and themes were used to guide the development of questions and the choice of instruments used in the survey (phase two).

\section{Participants and Recruitment}

Study phase one

Participants for study phase one were solely selfidentified LGBTQ students, interns and/or professionals in dietetics recruited using convenience and snowball sampling. An email was sent to individuals known to be "out" in dietetics and/or within the investigator's network 
with brief information about the study, an IRB-approved recruitment flyer, and the investigator's contact email requesting students, interns, and professionals who self-identify as LGBTQ and interested in participating in the study to contact the principal investigator. Upon receiving a response email, the investigator contacted all interested individuals to appraise them further of the study purpose and the time commitment required for participation and to set up a time to meet for an approximately 45 min semi-structured interview. Prior to all interviews, participants were read information about the study in order to make an informed consent. Only those who answered in the affirmative continued on into the interview. Participants who agreed to and completed the interview were enrolled in a raffle to receive one $\$ 100$ Amazon gift card. All individuals who were interested in participating were interviewed and their data included in the analyses.

\section{Study phase two}

Participants for study phase two were both LGBTQ and non-LGBTQ identified students, interns, and professionals in dietetics recruited using purposeful, convenience sampling. Emails containing similar content as in phase one plus a link to the online survey were sent to the participants in study phase two as well as individuals who represent a diverse group of registered dietitian nutritionists across the country, and groups known to direct or engage with Accreditation Council on Education in Nutrition and Dietetics (ACEND)accredited education programs. In total, 132 individuals, contacts for 30 Academy practice and member interest groups, and the directors of nine ACEND-accredited programs in the Boston area were contacted and asked to participate and/or to share the study link with individuals/groups in their networks. Prior to completing the online survey, participants were provided information about the nature of the study and then were asked to provide consent to participate. Participants were only allowed to complete the study if they indicated "yes" to the consent. Participants where then able to include their email to enter into a raffle for three $\$ 100$ Amazon gift cards.

\section{Data Collection}

Study phase one

All interviews were conducted in a private place where only the interviewer and interviewee would be able to hear the interview. Participants were asked if they would consent to tape recording of the interview prior to the interview start. All interviews were guided by a pre- determined semi-structured interview script designed to capture the "lived experience" of interview participants during their undergraduate and/or graduate academic programs, supervised practice, and professional engagement in dietetics. This interview format was chosen in effort to ensure all questions were asked and answered while allowing for additional probing and exploration of any salient information that arose over the course of the interview (Fontana \& Frey, 2003; Rabionet, 2011). The introduction and questions asked were the same for all participants to ensure consistency. All interviews were recorded with the participant's verbal permission for transcription at a later date. In addition, notes were made by the investigators during the interviews. Audio recordings were then transcribed verbatim inclusive of pauses, emphases and tone for analysis to best capture participant lived experiences (Patton 2002; McLellan et al., 2003).

Following transcription of eight interviews, the research team met to perform a preliminary qualitative analysis for major emergent themes to inform the development of questions to be asked on the survey. During this analysis, the main topic areas included in the semistructured interview formed the initial (a priori) descriptive codes. At that time, a number of major themes emerged repeatedly from the data and it was determined that the data for these major themes were "near saturation" (i.e., no major themes beyond those captured emerged). Two additional interviews were then conducted. These recordings were transcribed and analyzed. From this analysis it was confirmed that no additional major themes emerged and that the data for these major themes were "saturated". No additional interviews were undertaken.

Study phase two

Individuals who accessed the Qualtrics (Qualtrics, Provo, UT) survey were asked if they were a student or intern in an ACEND-accredited program, or a CDR credentialed professional (RDN, NDTR) to ensure that our data only reflected this group. Following this question, the survey included questions to obtain a) demographic information (including questions about sex, gender and sexual identity, b) whether or not respondents who answered gender non-binary were "out" to their peers, c) a validated measure of heterosexual attitudes toward homosexuality (Larsen et al., 1980; Marlin et al. 2018), d) questions about coursework or training in nutrition care of LGBTQ-identifying individuals, e) questions about degree of awareness about LGBTQ-identifying 
individuals and perceived responsibilities to society, and role in healthcare f) opinions on the Academy of Nutrition and Dietetics and ACEND-accredited programs and their practices of inclusion. The survey is included as a supplement to this manuscript.

\section{Measures}

Study phase one

Initial questions for the semi-structured interviews included questions to elicit demographic data: a) age, b) sex assigned at birth, c) gender identity, d) sexual identity, e) race/ethnicity, f) type and location of college/ university, supervised practice program attended, profession, g) year started the program or entered the profession. These questions were then followed by the interview questions: I) Overall, how would you describe your time as an [undergraduate/graduate/ intern/professional] in dietetics? 2) During your time as an [undergraduate/graduate/intern/professional], did you experience any "word or deed" that made you believe you were not welcome or wanted by the program or individuals within the program? Probes: If "yes", would you briefly describe the event(s)? How did the event(s) make you feel? Is there a word or words that best capture your feelings? Did the event(s) cause you to act differently afterwards? 3) If you did experience any "word or deed" that make you feel unwelcome or unwanted, what helped you to continue to move forward in your [academic or supervised practice program/professional work]? Probe: Was there something inside of you, or a particular person or group that helped you to persevere?

Study phase two

Demographic

Initial survey questions (questions I through 16 of the supplement) were designed to capture the demographics of our survey sample. Categories for gender were constructed based upon best practices for surveys of gender/sexuality published by the UCLA School of Law Williams Institute (https://williamsinstitute.law.ucla.edu/ visualization/lgbt-stats/?topic=LGBT\#density).

Interview Derived Questions

Demographic information was followed by survey questions that were derived from analysis of semistructured interviews with LGBTQ-identifying dietetics students, interns and professionals, consistent with our theoretical foundation (survey questions 34-50 of the supplement). Using the major emergent themes from our analyses, we developed 16 questions to capture data to further elucidate themes. Prior to distributing the survey to participants, the survey was reviewed by members of the LGBTQ community and suggested edits were incorporated into the survey prior to recruitment for this phase of the study.

Attitudinal \& Behavioral Constructs

The Attitudes of Heterosexuals toward Homosexuality (HATH-8) scale (Larsen et al., 1980; Marlin et al. 2018) was used in the survey to measure attitudes toward homosexuality. This 8-item survey is scored using a Likert-type scale with five items from "strongly agree" to "strongly disagree" (survey questions 26-33 of the supplement). This instrument was validated over three phases in a comprehensive process and found to be reliable and possess construct validity. All participants in the survey (those who did and those who did not identify as LGBTQ) were asked to complete the HATH8 scale. We chose this measure given its brevity and validity to assess attitudes toward homosexuality in heterosexual respondents, as the attitudes of this group were of greatest interest to the researchers.

\section{Analyses}

Study phase one

Content analysis was conducted by the three researchers by hand using the constant comparative method (Glaser \& Strauss, 1968; Boeije, 2002; Kolb, 2012). Following initial coding, the research group met again to determine secondary (axial) codes. From this inductive, iterative process, a final codebook was developed to guide the final analyses.

A draft code-book was created and discussed by all of the researchers. Further revisions of the code book were made by all researchers after the review of the initial draft. Once the code book was finalized, formal qualitative analysis was conducted by the three researchers. All three reviewed codes for concordance and any inconsistent coding was reviewed, discussed and finally determined.

\section{Validity enhancement activities}

Approximately three months following the interviews, two participants were contacted and asked if they would participate in a "member check" of their transcribed interviews consistent with the literature (Creswell, 2005). Participants who agreed were provided a summary of their interviews and asked to confirm or deny that the summary reflected what they had stated during the interview. Both participants agreed that the transcripts accurately reflected their 
interview responses.

During all stages of the analyses, all researchers engaged in reflexivity. This process, described by Valandra (2012) as a "shift from a focus on the data collected to the internal dialogue of researchers that helps them understand what is known and how it is known" (p. 204). Reflexivity was undertaken on an individual and group basis - often during the reviews of coding - to help ensure fidelity to the data.

The principal investigator (SD) entered the work positioned as female, cis-gender, heterosexual, and white, from a middle to upper middle class background who holds both a feminist and anti-racist standpoint. She recognizes that feminist theory and critical race theory "color" how she sees and interacts in and with the world. Throughout the data collection and analyses, she worked to examine her beliefs, judgments and practices and, when these beliefs were challenged, interrogated the dilemmas and challenges in the context of how her positionality may be at work. From this work, she was able to move beyond herself to engage with, listen to and acknowledge the lived experiences of participants who did not share her positionality, and work toward a greater understanding of the data.

As a self-identified member of the LGBTQ community, and an RDN, this research topic allowed $A B$ to explore her experiences in two separate worlds. At times, she was reminded of unpleasant situations in her dietetics education and internship. She used personal journaling and her life experience to understand and process her feelings on this topic. This practice helped her de-center herself and focus on actively engaging with others' stories as an $L G B T Q$ person in the field of dietetics during interviews and the coding process. $A B$ felt it important that she bring her LGBTQ community lens to call-out the subtle dynamics for LGBTQ folks that are often invisible to (well-meaning) cis-gendered, heterosexual people. In the coding process, there were a few occasions where she noted a subtle "LGBTQ dynamic" that merited discussion with the other coders. One particular example was settled and the coder remarked "oh wow, I never thought of it that way." There were also some examples where her coding of possible LGBTQ dynamics was challenged. With further discussion among all of the researchers, she recognized she coded on an assumption that could not be supported. Using her own experience to inform the understanding of nuanced LGBTQ dynamics helped her better amplify the voices and experiences shared with the researchers in this project. This research was what she needed 15 years ago.

This was the first qualitative research experience for $N M$, who entered this work identifying as a white, cisgender female graduate student and LGBTQ ally. While coding, she centered her focus on being as impartial, thorough, and consistent as possible. There were times, however, that she was reminded of things her close friends (both inside and outside the dietetics) that identify as LGBTQ had shared with her about their own experiences. This reminded her how important the work was, and how crucial it would be to listen to the perspectives of her fellow coders. She felt at times that she was the middle ground among coders, listening to the other coders' rationale for divergent perspectives that may have arisen, and at times participated as the tie-breaking vote. This position, as well as her own beliefs and background, helped her to think critically about which code made the most sense when coder assumptions were removed.

\section{Study phase two}

Survey demographic data were analyzed descriptively and presented as number and percent. The majority of questions on the survey (including the HATH-8) used Likert-type scales for responses. As such, the majority of hypothesis testing treated responses as ordinal variables and Chi-squared analysis with Fisher Exact Test was used given some cells contained less than 5 responses (McDonald, 2014).

For all hypothesis testing analyses, gender identity was grouped into man/woman as one group and non-binary (transgender man, transgender woman, gender queer, gender non-conforming, and different identity or "prefer not to answer") the other group. Sexuality was grouped as heterosexual/straight and non-heterosexual (gay, lesbian, bi-sexual, pansexual, asexual, queer, different identity and "prefer not to answer") for the other group.

\section{Results}

Ten $(n=10)$ participants completed the interviews. Two hundred eighteen individuals began the survey. Forty did not complete the survey. Of the $n=178,47$ respondents were not part of accredited programs nor credentialed professionals so their data were removed leaving the final sample $n=|3|$. Participant characteristics for both the qualitative and quantitative studies can be found in Table I. 
Table I. Participant characteristics

\begin{tabular}{|c|c|c|c|}
\hline Characteristic & & $\begin{array}{c}\text { Survey }(n=|3|) \\
n, \%\end{array}$ & $\begin{array}{c}\text { Interviews }(n=10) \\
n, \%\end{array}$ \\
\hline \multirow[t]{6}{*}{ Age (yrs) } & $18-29$ & 68 & 4 \\
\hline & $30-39$ & 31 & 5 \\
\hline & $40-49$ & 18 & 0 \\
\hline & $50-59$ & 9 & 0 \\
\hline & $60-69$ & 5 & I \\
\hline & $70+$ & 0 & 0 \\
\hline \multirow[t]{4}{*}{ Sex } & Male & 11 & 3 \\
\hline & Female & 119 & 7 \\
\hline & Intersex & 0 & 0 \\
\hline & Prefer not to answer & I & 0 \\
\hline \multirow[t]{8}{*}{ Gender identity } & Man & 11 & 3 \\
\hline & Woman & 115 & 5 \\
\hline & Transgender Man & 0 & I \\
\hline & Transgender Woman & 0 & 0 \\
\hline & Gender Queer & 0 & 0 \\
\hline & Gender Non-conforming & 2 & 0 \\
\hline & Different Identity & 3 & I \\
\hline & Prefer not to answer & 0 & 0 \\
\hline \multirow[t]{9}{*}{ Sexual identity } & Gay & 5 & 3 \\
\hline & Lesbian & 9 & 3 \\
\hline & Heterosexual/Straight & 91 & 0 \\
\hline & Bi-sexual & 19 & 2 \\
\hline & Pansexual & 0 & 0 \\
\hline & Asexual & 0 & 0 \\
\hline & Queer & 6 & I \\
\hline & Different identity & 0 & I \\
\hline & Prefer not to answer & I & 0 \\
\hline \multirow[t]{5}{*}{ Race } & American Indian/Alaska Native & 2 & 0 \\
\hline & Asian & 10 & 0 \\
\hline & Black/African American & 9 & 0 \\
\hline & Native Hawaiian/Pacific Islander & 0 & 0 \\
\hline & White & 108 & 10 \\
\hline \multirow[t]{2}{*}{ Ethnicity } & Hispanic/Latinx & 13 & 1 \\
\hline & Not Hispanic/Latinx & 115 & 9 \\
\hline \multirow[t]{7}{*}{ Annual income $(\$)$} & $0-1000$ & 23 & \\
\hline & $1001-5000$ & 18 & \\
\hline & $5001-10000$ & 6 & \\
\hline & $10001-50000$ & 19 & \\
\hline & $50001-75000$ & 26 & \\
\hline & $75001-100000$ & 32 & \\
\hline & Prefer not to answer & 7 & \\
\hline
\end{tabular}




\begin{tabular}{|c|c|c|}
\hline \multirow[t]{4}{*}{ Stage in professional development } & Undergraduate Student & 12 \\
\hline & Graduate Student & 19 \\
\hline & Intern & 29 \\
\hline & Practitioner & 70 \\
\hline \multirow[t]{6}{*}{ Years engaged in profession (years) } & 1 & 7 \\
\hline & 2 & 10 \\
\hline & 3 & 9 \\
\hline & $4-5$ & 52 \\
\hline & $6-10$ & 21 \\
\hline & $10+$ & 30 \\
\hline \multirow[t]{2}{*}{ RDN } & Yes & 70 \\
\hline & No & 61 \\
\hline \multirow[t]{2}{*}{ NDTR } & Yes & 3 \\
\hline & No & 128 \\
\hline \multirow[t]{4}{*}{ Highest level of education } & $\mathrm{AA}$ & 8 \\
\hline & BS & 57 \\
\hline & MS & 52 \\
\hline & Doc & 12 \\
\hline \multirow[t]{2}{*}{ Educator/Preceptor? } & Yes & 55 \\
\hline & No & 75 \\
\hline \multirow{6}{*}{$\begin{array}{l}\text { How many years as an educator or } \\
\text { preceptor? }\end{array}$} & 1 & 6 \\
\hline & 2 & 5 \\
\hline & 3 & 3 \\
\hline & $4-5$ & 9 \\
\hline & $6-10$ & 11 \\
\hline & $10+$ & 19 \\
\hline \multirow[t]{8}{*}{ Section of dietetics industry } & Clinical Inpatient & 14 \\
\hline & Clinical Outpatient & 8 \\
\hline & Clinical Long Term Care & 1 \\
\hline & Education/Research & 21 \\
\hline & Community & 7 \\
\hline & Food Nutrition Management & 2 \\
\hline & Consultant/Business & 2 \\
\hline & Other & 30 \\
\hline \multirow[t]{3}{*}{ Gender out? } & Completely & 0 \\
\hline & Partially & 3 \\
\hline & Not at all & 2 \\
\hline \multirow[t]{3}{*}{ Sexuality out? } & Completely & 14 \\
\hline & Partially & 11 \\
\hline & Not at all & 13 \\
\hline
\end{tabular}




\section{Qualitative}

Ten total interviews were conducted with LGBTQ-identified individuals between March and September 2020. Audio recordings for the semi-structured interviews averaged 41:22 minutes (range 17-84 min). Interrater concordance for codes assigned was initially $87 \%$. All codes were resolved through discussion among the coders. Analysis of the semi-structured interview data revealed three major themes and a number of subthemes as outlined in Table 2.

Table 2. Themes, subthemes and representative quotes from semi-structured interviews $(n=10)$.

\begin{tabular}{|c|c|c|}
\hline Theme & Subtheme & Representative quote(s) \\
\hline \multirow[t]{3}{*}{$\begin{array}{l}\text { General impressions of } \\
\text { experience of academics, } \\
\text { supervised practice, job }\end{array}$} & Good & $\begin{array}{l}\text { - "l loved it" (AH) } \\
\text { - "Positive" (HL) } \\
\text { - "Pleasant" (JP) }\end{array}$ \\
\hline & Neutral & $\begin{array}{l}\text { - "...neutral compared to other activities I took } \\
\text { in at [redacted university]" (ED) }\end{array}$ \\
\hline & Bad & $\begin{array}{l}\text { - "stressful" (AH) } \\
\text { - "frustrating" (KA) }\end{array}$ \\
\hline \multirow[t]{4}{*}{$\begin{array}{l}\text { Overt "underminers" } \\
\text { associated with the } \\
\text { experience of academics, } \\
\text { supervised practice, job* }\end{array}$} & $\begin{array}{l}\text { Behavior of others: } \\
\text { - Heteronormative assumptions/ } \\
\text { talk } \\
\text { - Misgendering/Pronouns }\end{array}$ & $\begin{array}{l}\text { - "...I mean, it was always awkward when } \\
\text { people just assume heterosexuality, um, which } \\
\text { happened a lot" (JC) } \\
\text { - "They're just fitting assumptions around who I } \\
\text { must be attracted to. Who I must want to be } \\
\text { in a relationship with" (AH) } \\
\text { - "Like, the people that are getting married and } \\
\text { having babies... are clearly, like, congratulated } \\
\text { at team meetings and prized, and the people } \\
\text { that don't fit that norm don't really have the } \\
\text { same recognition" (KS) } \\
\text { - "I still get misgendered a lot" (JC) }\end{array}$ \\
\hline & $\begin{array}{l}\text { Perceptions of others: } \\
\text { - Due to age } \\
\text { - Due to religion }\end{array}$ & $\begin{array}{l}\text { - "...l'm dealing with an older generation and I } \\
\text { could just tell that everyone was much more } \\
\text { conservative" (KS) } \\
\text { - "...but I did experience people who clearly did } \\
\text { not... like gay people... on religious grounds." (KA) }\end{array}$ \\
\hline & $\begin{array}{l}\text { Having to be the LGBTQ } \\
\text { "culture broker" }\end{array}$ & $\begin{array}{l}\text { - "...I do... want to be a resource for people... } \\
\text { and I felt at times people would take } \\
\text { advantage of that... and they were invasive" } \\
\text { (KF) }\end{array}$ \\
\hline & $\begin{array}{l}\text { Lack of LGBTQ educational/ } \\
\text { experiential content in accredited } \\
\text { programs }\end{array}$ & $\begin{array}{l}\text { - “...the experiences of trans folks, and } \\
\text { LGBTQ folks and higher rates of disease and } \\
\text { eating disorders, etc. was not really...um, we } \\
\text { weren't really... we didn't explore that [in their } \\
\text { program]. So it was ignored" (AH) } \\
\text { - "And, like, all of our learning needs codes are based } \\
\text { around the binary..." (JC) } \\
\text { - "...like my education, my internship, it wasn't really } \\
\text { brought up at all [queer health-related topics]" } \\
\text { (HL) } \\
\text { "...there are other nutritional implications of } \\
\text { the queer identity other than, you know, HIV" } \\
\text { (HL) } \\
\text { - "... just wish this was a piece of a didactic } \\
\text { program" (JP) }\end{array}$ \\
\hline
\end{tabular}




\begin{tabular}{|c|c|c|}
\hline \multirow[t]{2}{*}{$\begin{array}{l}\text { Covert "underminers" } \\
\text { associated with the } \\
\text { experience of academics, } \\
\text { supervised practice, job }\end{array}$} & $\begin{array}{l}\text { Behaviors of self: } \\
\text { - Self-editing/ censoring/distancing } \\
\text { - Lying/hiding/closeting }\end{array}$ & $\begin{array}{l}\text { - "...even if people still don't have a problem } \\
\text { with it...you still ha- you never. Stop. Editing } \\
\text { yourself...you have to be on guard all the } \\
\text { time" (KA) } \\
\text { - "It's exhausting because you -you don't want } \\
\text { to slip up" (KA) } \\
\text { - "Not only did I not share [about their } \\
\text { sexuality] but I also lied" (ED) } \\
\text { - "It's not something that I like to tell people, } \\
\text { but if it like, comes up, it comes up..." (HL) } \\
\text { - "...so I....again, I like, completely and } \\
\text { intentionally pass as straight at my job" (KS) }\end{array}$ \\
\hline & $\begin{array}{l}\text { Behavior of others: } \\
\text { - Microaggressions }\end{array}$ & $\begin{array}{l}\text { - "...I was getting married to my partner - } \\
\text { and I needed to miss some of my clinical } \\
\text { rotations... and the professor kind of made a } \\
\text { face at me..." (JC) } \\
\text { - "...I remember being in conference rooms or } \\
\text { something and hearing people talk negatively } \\
\text { about gay people, and you just had to sit there } \\
\text { and suck it up." (KA) } \\
\text { - "...I wanted to, you know, go and teach } \\
\text { transgender nutrition. And, um... one day } \\
\text { one of my professors said 'Are you sure you } \\
\text { want to mix your personal life with your } \\
\text { professional life?"' (KF) }\end{array}$ \\
\hline \multirow{5}{*}{$\begin{array}{l}\text { Supporters associated with } \\
\text { the experience of academics, } \\
\text { supervised practice, job }\end{array}$} & Community: & \multirow[b]{2}{*}{$\begin{array}{l}\text { - "...I think I have always had some form of } \\
\text { community to rely on and to talk with to get } \\
\text { through" (ED) } \\
\text { - "...I, surprisingly, was really impressed with } \\
\text { how open minded... my classmates who } \\
\text { identified as [redacted religion] were" (KS) } \\
\text { - "As soon as I saw it [rainbow sticker] I felt } \\
\text { welcome. It definitely helped me feel as if } \\
\text { I was part of a community already without } \\
\text { really knowing it" (ED) }\end{array}$} \\
\hline & $\begin{array}{l}\text { - Groups } \\
\text { - People with supportive } \\
\text { characteristics } \\
\text { - Signs/symbols of support }\end{array}$ & \\
\hline & Individual: & \multirow[b]{2}{*}{$\begin{array}{l}\text { - "...I started a weekly game night with a } \\
\text { bunch of friends who were mostly queer...just } \\
\text { knowing they were there. They had my back } \\
\text { and, the rest of the world was shitty, but we... } \\
\text { were going to be laughing about stuff" (JC) } \\
\text { - "...I have enough awareness, and put enough } \\
\text { time into my own form of therapy - you know, } \\
\text { seeing a therapist..." (ED) }\end{array}$} \\
\hline & $\begin{array}{l}\text { - Friends/allies } \\
\text { - Therapist/Mental Health } \\
\text { Professional }\end{array}$ & \\
\hline & Passion for the field & $\begin{array}{l}\text { - "...curiosity and, like, feeling like I was finding } \\
\text { a vocation and a career and feeling excited } \\
\text { about that" (KS) }\end{array}$ \\
\hline
\end{tabular}

*We use the term underminer here to describe persons, places or things that undermined the participants' experience of or progress through their dietetics experience.

In general, when asked to consider their academic program, supervised practice or job independent of their gender identity/sexuality participants described their experiences as "good". The most frequent response was that they found their academic programs, supervised practice or job "stressful", but the stress was related to the rigor of the experience independent of the participant's gender identity/sexuality. 
When participants were asked to recall their experiences in their academic, supervised practice and jobs considering their gender identity/sexuality, a number of overt and covert underminers were revealed. One frequent overt underminer was associated with heteronormative assumptions and talk exhibited by professors, preceptors and co-workers. As one participant stated, "Oh, like, we're having a going away party for so and so. Like, do we invite the husbands and the kids?", Additionally, participants often felt that they had to be the LGBTQ "culture broker" (Jezewski \& Sotnik, 200I). For those participants who were comfortable being "out" or not closeting, they found they were often asked to explain to gender binary and/or straight-identifying individuals LGBTQ culture and/or healthcare needs. This often included explaining the importance of using the correct pronouns for gender non-conforming patients/clients. As one participant stated, "I do feel I was able to support them [fellow dietitians], and a lot of things, like the vocabulary around the...they were very confused...", Another overt underminer was the perception of others regarding LGBTQ-identifying people. This was most frequently presented as being related to age or religion. As one participant shared, "Um, I think I would definitely have hesitation [about coming out]. Um, specifically for the couple of the preceptors that are in that older generation".

Perhaps most important for ACEND-accredited dietetics education program curricula, participants consistently reported that they received little if any didactic or experiential information or training in the nutrition care of LGBTQ patients and clients. For a good number of our participants, this omission created a noninclusive atmosphere within their training/experiential programs as well as put a burden on participants to provide that education and training to their peers, and at times preceptors and/or supervisors. As one participant noted "...it makes me question their commitment to diversity...maybe there's no professors that want to invest their time in that topic [the LGBTQ community]".

Covert underminers (such as microaggression or "closeting") of educational and/or experiential programs or dietetics practice most often elicited a change in participant behaviors in attempt to "erase" their genderidentity and/or sexuality, or suggested to participants that they were unwelcome and/or unwanted in their programs or jobs. One Lesbian identified participant explained "...l did not want to have to have that conversation with people. So, I would give my girlfriends male names when I talked about them, and just pass as straight. And that was - I just did that to avoid...", Another participant reported microaggressions "... if we were talking about people who were gay, when we talked about those things, they were always in a whisper".

Our participants related a number of "supporters" associated with their experience in academics, supervised practice and their professional settings. Supporters took both individual and group forms. Individual friends/ allies and therapist/mental health professionals were frequently used for support. One participant related that they started a weekly game night with their queer friends. Another participant began working with a therapist which they found "integral to... [their] survival". Group supporters included large groups of community members such as a student PRIDE organization. Other participants spoke positively of signs/symbols of support that they encountered in their settings. Some mentioned "rainbow" stickers or pins which to them felt welcoming. Finally, many of our participants reported that their passion for the field of nutrition/dietetics was what allowed them to persevere in their academicl internship programs in spite of the negative experiences they encountered. As one participant stated, "....the fact that you enjoy what you're doing continues to drive you to move forward".

\section{Survey}

The survey was completed by both LGBTQ and nonLGBTQ self-identifying individuals. Results from the HATH-8 scale analyzed by sexuality are presented in Table 3. There were statistically significant differences by sexual identity to a number of scale items: LGBTQidentified individuals agreed more significantly than their heterosexual peers that homosexuals should be allowed to work with children and that homosexuals should have social equality. LGBTQ-identified participants disagreed more strongly than their heterosexual peers that homosexuals should be barred from the teaching profession. There were no statistically significant differences in the responses $(n=128)$ to the HATH-8 scale when stratified by gender identity. 
Table 3. HATH-8 bias scale responses by sexuality $(n=128)$

\begin{tabular}{|c|c|c|c|}
\hline Item & $\mathbf{X}^{2}$ & df & $\mathbf{p}^{*}$ \\
\hline It would be beneficial to society to recognize homosexuality as normal. & 9.75 & 4 & $0.0240 *$ \\
\hline Homosexuals should not be allowed to work with children. & 6.85 & 3 & $0.0490 *$ \\
\hline All homosexual bars should be closed down. & 4.12 & 3 & 0.2163 \\
\hline Homosexuals should be given social equality. & 10.27 & 4 & $0.0078 *$ \\
\hline Homosexuals should have equal opportunity employment. & 5.65 & 3 & 0.1136 \\
\hline There is no reason to restrict places where homosexuals work. & 4.43 & 4 & 0.2362 \\
\hline Homosexuals should be barred from the teaching profession. & 7.90 & 3 & $0.0130 *$ \\
\hline Homosexuals should not be allowed to marry. & 4.92 & 4 & 0.1746 \\
\hline
\end{tabular}

*Fisher's Exact Test $p<0.05$

Of the $n=131$ participants who answered our question about the depth and breadth of coursework/training in assessment/care of LGBTQ-identifying individuals received by students, interns, and professionals, $28.0 \%$ received coursework/training, and $72.0 \%$ did not. When those who did receive coursework/training were asked about the extent of that coursework/training, $\quad(n=33$ participants) $69.7 \%$ received "a little", 24.2\% received "some", 3.0\% received "a moderate amount" and $3.0 \%$ received "a lot". No one received "extensive" coursework/training.

LGBTQ-identified participants felt that it was more important to them personally $X^{2}(4, n=118) 16.20$, $p=0.0010$, and to the profession $X^{2}(4, n=118) 8.76$, $p=0.0392$, that dietetics students/interns/professionals receive coursework/education/continuing education related to nutrition assessment and care of individuals who identify as LGBTQ than heterosexual-identifying participants. No differences were observed by gender identity.

When participants were asked to indicate their awareness of issues, identified in phase one, encountered by LGBTQ-identifying individuals/community, a number of differences were seen when grouped by gender identity and sexuality. When grouped by gender identity, LGBTQ participants reported greater awareness about peer visibility $X^{2}(4, n=117) \quad 11.79, p=0.0220$, and safety to disclose $X^{2}(4, n=117)$ 19.22, $p=0.0018$ than cis-gender participants. When grouped by sexuality, LGBTQ respondents were more aware of all issues than their heterosexual peers (Table 4).

Table 4: How aware are you of the following as relates to the LGBTQ community by sexuality $(n=I I 7)$

\begin{tabular}{|c|c|c|c|}
\hline Item & $\mathrm{X}^{2}$ & df & p \\
\hline Healthcare needs & 13.89 & 4 & $0.0068^{*}$ \\
\hline Culture & 38.86 & 4 & $<\left.0.000\right|^{*}$ \\
\hline Peer visibility & 30.41 & 4 & $<\left.0.000\right|^{*}$ \\
\hline Historical trauma & 10.70 & 4 & $0.0248 *$ \\
\hline Power dynamics & 14.98 & 4 & $0.0040 *$ \\
\hline Social dynamics & 11.54 & 4 & $0.0255^{*}$ \\
\hline Safety to self-disclose & 24.06 & 4 & $<\left.0.000\right|^{*}$ \\
\hline Fear of judgement & 32.83 & 4 & $<\left.0.000\right|^{*}$ \\
\hline Use of pronouns & 24.33 & 4 & $<0.0001^{*}$ \\
\hline
\end{tabular}

*Fisher's Exact Test

$p<0.05$ 
When participants $(n=115)$ were provided a number of items and then asked to indicate the level of responsibility LGBTQ-identifying individuals (rather than heterosexual, cis-gender individuals/community) are for them, cis-gender participants indicated that LGBTQidentified individuals were more responsible for "positive representation of the LGBTQ community as a whole" $X^{2}(4, n=116)$ 15.18, $p=0.0089$. When grouped by sexuality, significant differences were seen between heterosexual and LGBTQ-identified participants for "bringing forth new perspectives to the patient/client care team" $X^{2}(4, n=116)$ 15.18, $p=0.0027$, "lifting up the voices of LGBTQ or other historically excluded individuals" $X^{2}(4, n=116) \quad \| .04, p=0.0277$, and "advocating for LGBTQ patients/clients" $X^{2}(4, n=116)$ 16.53, $p=0.0028$, with heterosexual participants indicating that LGBTQ-identified individuals were more responsible for those items.
The degree of agreement, frequency, or safety to a number of questions derived from the semi-structured interviews significantly differed when data were analyzed by gender and by sexuality. When grouped by gender identity, LGBTQ-identified participants indicated "more frequently" in response to "How frequently have you hesitated to join situations/gatherings related to your academics, supervised practice and/or professional position in dietetics because of your gender identity?" $X^{2}(4, n=116) 30.45, p=0.0058$ and "How frequently did you feel you needed to alter your 'presentation of self' (how you appear, mannerisms, etc.) to others during your academics, supervised practice and/or professional position in dietetics?" $X^{2}(4, n=116)$ 12.32, $p=0.0086$. When grouped by sexuality (Table 5), significant differences were seen in responses to all items EXCEPT "LGBTQ-identifying practitioners contribute unique perspective(s) that enhance the quality of care/care team for all patients/clients".

Table 5: Interview-derived questions analyzed by sexuality $(n=\mid / 6)$

\begin{tabular}{|c|c|c|c|}
\hline Item & $\mathrm{X}^{2}$ & df & p \\
\hline $\begin{array}{l}\text { LGBTQ-identifying practitioners contribute unique perspective(s) } \\
\text { that enhance the quality of care/care team for all patients/clients. }\end{array}$ & 6.22 & 3 & 0.0906 \\
\hline $\begin{array}{l}\text { LGBTQ-identifying practitioners contribute unique perspective(s) } \\
\text { that enhance the quality of care/care team for LGBTQ-identifying } \\
\text { patients/clients. }\end{array}$ & 9.54 & 4 & $0.0265^{*}$ \\
\hline $\begin{array}{l}\text { How frequently have you hesitated to join situations/gatherings } \\
\text { related to your academics, supervised practice and/or professional } \\
\text { position in dietetics because of your gender identity? }\end{array}$ & 12.67 & 4 & $0.009 \mid *$ \\
\hline $\begin{array}{l}\text { How frequently have you hesitated to join situations/gatherings } \\
\text { related to your academics, supervised practice and/or professional } \\
\text { position in dietetics because of your sexual orientation? }\end{array}$ & 22.73 & 4 & $<0.0001 *$ \\
\hline $\begin{array}{l}\text { How frequently did you feel you needed to alter your } \\
\text { "presentation of self" (how you appear, mannerisms, etc.) } \\
\text { to others during your academics, supervised practice and/or } \\
\text { professional position in dietetics? }\end{array}$ & 18.24 & 4 & $0.0011 *$ \\
\hline $\begin{array}{l}\text { How frequently did you feel you needed to alter your } \\
\text { communication content (relate aspects of your personal life, } \\
\text { social activities, etc.) to others during your academics, supervised } \\
\text { practice and/or professional position in dietetics? }\end{array}$ & 29.81 & 4 & $<0.000 I^{*}$ \\
\hline $\begin{array}{l}\text { How often did you feel you needed to maintain strict boundaries } \\
\text { between your personal vs. professional life during your academics, } \\
\text { supervised practice and/or professional position in dietetics? }\end{array}$ & 14.86 & 4 & $0.0038 *$ \\
\hline $\begin{array}{l}\text { On the whole, how safe do/did you feel "being your true/ } \\
\text { authentic self" during your academics, supervised practice and/or } \\
\text { professional position in dietetics? }\end{array}$ & 18.14 & 4 & $0.0007^{*}$ \\
\hline
\end{tabular}

*Fisher's Exact Test

$p<0.05$ 
Finally, participants $(n=116)$ were asked to rate the Academy of Nutrition and Dietetics, didactic/academic programs in dietetics, supervised practice programs and the profession of dietetics in terms of the "degree of welcoming" they felt these groups were. When grouped by gender identity, there were no statistically significant difference between groups. When grouped by sexuality, LGBTQ-identified participants significantly rated the Academy $X^{2}(4, n=116)$ 9.80, $p=0.0328$ and supervised practice programs $X^{2}(4, n=115) \quad 11.36, p=0.0242$ "less welcoming" than heterosexual participants.

\section{Discussion}

Our mixed methods research, grounded in Feminist Standpoint theory, was conducted to characterize the lived experiences of LGBTQ-identifying individuals in dietetics. Consistent with Feminist Standpoint theory, we used the themes and responses elicited through the semi-structured interviews of LGBTQ self-identified individuals to inform the questions included on the survey of both LGBTQ and non LGBTQ identified participants. Two major findings have significant implications for dietetics: the existence of both explicit and implicit antiLGBTQ bias in dietetics spaces, and a lack of education and training on care of the LGBTQ-identified patient/ client.

Most evident from our work is that explicit and implicit bias exists in dietetics spaces. Explicit bias against LGBTQ-identified individuals, confirmed in our study by responses to the HATH-8 scale, was evident in our non-LGBTQ identified participants. Implicit bias was identified through our semi-structured interviews of LGBTQ-identified participants. No one setting emerged as being more problematic than another. Unfortunately, the presence of bias against LGBTQ-identifying students is not new. Discrimination and harassment have been reported in numerous studies on a wide-range of campuses (Rankin et al, 2010); Seelman et al. 2017; Tetreault et al., 2013). Many studies have reported effects of anti-LGBTQ bias on LGBTQ-identifying students including negative effects on academic performance and mental and physical health (Oswalt \& Wyatt, 2011; Woodford and Kulick 2014; Woodford \& Kulick 2015). Therefore, although concerning, it is not surprising that bias against LGBTQ-identifying dietetics students would exist.

Additionally, anti-LGBTQ bias toward patients/clients has been documented in health care professionals during their training. In their systematic review, Morris et al. (2019) reviewed $n=13$ articles which described programs designed to reduce bias towards LGBTQidentifying patients among medical, nursing and dental students in order to determine which programs were effective in bias reduction. They concluded that, although there was "promising support" for anti-bias programs to improve knowledge and comfort levels among students, none of the interventions reviewed assessed change in bias among students or providers.

A lack of adequate education and training among dietetics students, interns, and professionals regarding the care of LGBTQ-identified patients/clients was identified in our work, though unfortunately, this need was viewed as problematic only among our LGBTQidentified participants. Given the health disparities extant among LGBTQ-identifying individuals, it is clear that effective programs must be designed to remove bias and improve education and training among all healthcare providers to allow for the provision of equal quality of care. Our work presents compelling evidence that ACEND-accredited education and supervised practice programs must add (if currently not present) or expand upon content that not only addresses anti-LGBTQ bias among students, interns, faculty and preceptors, but also provides content on best practices for care of LGBTQ-identifying individuals. Currently there are no knowledge requirements nor competencies required for ACEND-accredited programs that specifically address understanding and/or competency to care for LGBTQidentifying patients and clients. Also, there is no specific requirement for credentialed professionals to maintain continuing education around anti-LGBTQ bias reduction or nutrition care of LGBTQ-identifying patients/clients. Our work, and the work of others, suggest that this must change.

Specifically, the Academy (through its credentialing agency, the Commission on Dietetic Registration or CDR) and ACEND must mandate anti-bias training for both membership and accredited education programs, respectively. Recently, CDR mandated a minimum of I CEU each 5 year credentialing period in "ethics" for all credentialed professionals. We strongly recommend that a similar requirement be established for continuing education in diversity and inclusion. In the case of ACEND, training must be mandated for both students/ interns and faculty/preceptors. Currently, there are no ACEND nor Academy educational webinars that specifically address bias reduction and inclusion as 
it relates to LGBTQ-identifying students, interns or patients/clients.

Additionally, ACEND must mandate for accreditation both knowledge requirements and competencies for students/interns on both anti-LGBTQ bias and care of the LGBTQ-identified patient/client. The current draft of the ACEND 2022 standards for Didactic Program in Dietetics (DPD) include revisions and additions to the 2017 standards designed to improve diversity, inclusion and "cultural competency"(ACEND, 2021). We are hopeful that these revisions will be ratified in a form that will mandate all accredited programs to demonstrate these standards are met to maintain program accreditation.

We believe that our study is strengthened by its mixed methods design. The inclusion of both semi-structured interviews and a survey allowed us to explore in greater depth the issues that our participants raised and quantify biases. We also believe our theoretical foundation provided strength to the work by ensuring that our survey included questions that address issues most salient for members of the LGBTQ community in dietetics. It was essential to the strength of the research to construct our survey including input and direction from the LGBTQ-identified community. This became most evident when we had a member of the community "call in" the principal investigator to question how the survey questions were derived. They expressed concern that individuals/researchers involved in creating the survey were not a part of the LGBTQ community. This individual was grateful to hear not only that one of the researchers is a member of the community, but also that the community at large were instrumental in defining the survey content.

Our work does have limitations. The sample size for study phase one was small and may not reflect the experiences of all LGBTQ-identifying individuals, particularly those of diverse demographics (e.g., race/ ethnicity, socioeconomic status). We did not address intersectionality in our study, therefore it is unclear how those who hold multiple identities experience dietetics as students, interns and/or professionals. Additionally, the non-random sampling of participants in our survey may have created bias that reduces the validity/generalizability of our survey results. Finally, we did not collect data on the geographical location of our participants. Different areas of the US are, in general, more conservative or more liberal which has been associated with different levels of anti-LGBTQ bias (White Hughto et al, 2016; Hswen et al., 2020). Where our participants lived may have influenced our results.

\section{Conclusion}

Our research contributes significantly to the literature by characterizing the experiences of LGBTQ-identifying individuals within academic, supervised practice, and professional settings in dietetics. It supports a call for the Academy and ACEND to significantly improve and mandate requirements for education/training and content/continuing education for students, interns, and professionals in accredited dietetics programs and practice on both inclusive practices/bias reduction and the care of LGBTQ-identifying patients/clients. LGBTQidentifying students, interns, professionals, and patients/ clients exist, and it is incumbent upon educators, preceptors and managers to ensure that dietetics spaces are inclusive and welcoming and our patients/clients receive quality care.

\section{Acknowledgement}

The authors would like to thank Kate G Burt, PhD, RDN for her review of a draft of this manuscript.

\section{Bios}

\section{Michele A. "Shelly" DeBiasse, PhD, RDN}

Michele A. "Shelly" DeBiasse, PhD, RDN (she/they) is Clinical Associate Professor and Director, Programs in Nutrition at Boston University/College of Health \& Rehabilitation Sciences: Sargent College, Affiliated Faculty in the Women's, Gender \& Sexuality Studies program and the Center for Innovation in Social Sciences in the College of Arts and Sciences, and Affiliated Researcher, with the Center for Antiracist Research, Boston University, Boston, MA, USA. Her PhD in Nutrition \& Metabolism was awarded by the department of Graduate Medical Sciences, Boston University School of Medicine. She received her MS in Clinical Nutrition from Rush University, and completed her dietetic internship at Rush-Presbyterian-St. Luke's Medical Center, both in Chicago, IL, USA. Her PhD dissertation, The Theory of Planned Behavior and Implementation Intentions to Improve Fruit and Vegetable Intake among Women with Low Socioeconomic Status, afforded her three first-author publications, and helped spark her scholarship interests to identify ways to better the lives of women and other historically excluded groups. Her current research centers upon issues related to equity, 
diversity, inclusion, and social justice in healthcare and healthcare professions (particularly dietetics), and how gender may contribute to challenges often associated with female-dominate healthcare professions.

\section{Amy Branham, MS, RDN, LDN}

Amy Branham, MS, RDN, LDN (she/her) currently works for UMass Extension as a SNAP-Ed Multi-Level Specialist. In this role she oversees policy, systems and environmental change strategies to support SNAP-Ed programming across Massachusetts. Amy received her MS in Nutrition from Boston University, and completed her dietetic internship at the University of Massachusetts Memorial Medical Center. In addition to the coursework and internship, she also completed independent research resulting in an MS thesis component, A Qualitative Study of Influences on Food Behaviors of Urban, Schoolage Children. Through this research, career experience, and lived experience as an LGBTQ person, Amy has continued to explore themes of inclusion, opportunity, and privilege within the nutrition and dietetics fields. This work, independent of her current professional role, resulted in connecting with Dr. DeBiasse to engage in formal research projects of shared interest. In both her professional role and independent research activities, Amy enjoys thinking big and creating strategies and vision to support future programs and program equity.

\section{Nicole McFarland, MS}

Nicole McFarland, MS (she/her) is a current dietetic intern at Newton-Wellesley Hospital in Newton, MA, USA. She received her BS in Nutrition and Dietetics from Simmons University in Boston, MA, USA, where she was granted the Nancie A. Herbold Humanitarian Award for a demonstrated commitment to social justice. Her MS in Nutrition was awarded from Boston University's Sargent College. While she was a student there, she was given the opportunity to work as a graduate assistant for Dr. DeBiasse, who graciously brought her onto this project. As her first hands-on experience in research, this work opened her eyes to the many challenges LGBTQidentifying individuals in dietetics face. Currently her areas of professional interest include clinical nutrition as well as eating disorder prevention and treatment.

\section{References}

Accreditation Council for Education in Nutrition and Dietetics. (August I, 2021). Proposed 2022 Standards. https://www. eatrightpro.org/acend/accreditation-standards-fees-andpolicies/proposed-2022-standards

Alessi, E. J., Sapiro, B., Kahn, S., \& Craig, S. L. (2017). The firstyear university experience for sexual minority students: A grounded theory exploration. Journal of LGBT Youth, 14(I), 71-92.

Burt, K.G., Ruder, E., DeBiasse, M.A. (in press). We need data! The importance of collecting more and better data to achieve a diverse, inclusive profession. The Digest.

Boeije, H. (2002). A purposeful approach to the constant comparative method in the analysis of qualitative interviews. Quality and Quantity, 36(4), 391-409.

Carlson, E. S., Gammage, S., \& Barrientos, J. (20/5). Is Prejudice against LGBT Persons Linked to Increased HIV Vulnerability for Heterosexual Men? Lessons for Human Rights Advocacy from South America. Journal of Human Rights Practice, 7(2), 327-34l. https://doi.org//0.1093/ jhuman/huv003

Commission on Dietetic Registration. (2019). Registry Statistics. (November 25). https://www.cdrnet.org/registry-statistics ?id=3702\&action $\times m=$ ByDemographics

Creswell, J. W. (2005). Educational research: Planning, conducting, and evaluating quantitative and qualitative research (2nd ed.). Upper Saddle River, NJ: Pearson

DeBiasse, M. A., Qamar, Z., amd Burt, K. G. (202I). A social media intervention for dietetics professionals to increase awareness about racial/ethnic diversity and inclusion in dietetics: Black voices centered. Journal of Critical Dietetics, 6(I), 40-48.

Eliason, M.J., Dibble, S.L., Robertson, P.A. (201I) Lesbian, gay, bisexual, and transgender (LGBT) physicians' experiences in the workplace. Journal of Homosexuality. 58(10), 1355137|. doi:10.1080/00918369.2011.614902

Fontana, A., \& Frey, J. H. (2003). The Interview: From structured questions to negotiated text in Denzin, NK \& Lincoln, YS (eds). Collecting and interpreting qualitative materials.

Glaser, B. G., Strauss, A. L., \& Strutzel, E. (1968). The discovery of grounded theory; strategies for qualitative research. Nursing Research, 17(4), 364.

Harding, S. (2006). Feminist Standpoints. In Hesse-Biber (Ed.), Handbook of Feminist Research: Theory and Praxis. Sage Publications, Inc. Newbury Park, CA

Hsieh, N. (2014). Explaining the mental health disparity by sexual orientation: The importance of social resources. Society and Mental Health. 4(2), 129-146.

Hswen, Y., Zhang, A., Sewalk, K. C., Tuli, G., Brownstein, J. S., \& Hawkins, J. B. (2020). Investigation of Geographic and Macrolevel Variations in LGBTQ Patient Experiences: Longitudinal Social Media Analysis. J. Med. Internet Res, 22, el7087. 
Jezewski, M. A., \& Sotnik, P. (200I). Culture brokering: Providing culturally competent rehabilitation services to foreign-born persons. Buffalo, NY: Center for International Rehabilitation Research Information and Exchange.

Kates, J., Ranji, U., Beamesderfer, A., et al. (May 2018). Health and access to care and coverage for Lesbian, Gay, Bisexual, and Transgender Individuals in the US. Racial Equity and Health Policy. https://www.kff.org/disparities-policy/issuebrief/health-and-access-to-care-and-coverage-for-lesbiangay-bisexual-and-transgender-individuals-in-the-u-s/

King M, Semlyen J, Tai SS, et al. (2008). A systematic review of mental disorder, suicide, and deliberate self-harm in lesbian, gay and bisexual people. BMC Psychiatry. 8(I),70. doi:10.1186/147|-244X-8-70

Kolb, S. M. (2012). Grounded theory and the constant comparative method: Valid research strategies for educators. Journal of Emerging Trends in Educational Research and Policy Studies, 3(1), 83-86.

Lund A, Yoder Latortue K, Rodriguez J. (202I) Dietetic training: Understanding racial inequity in power and privilege. Journal of the Academy of Nutrition and Dietetics, 121 (8), 1437-1440.

Larsen K.S., Reed M., Hoffman S. (1980) Attitudes of heterosexuals toward homosexuality: A Likert type scale and construct validity. The Journal of Sex Research. 16(3),245-257. doi:I0.1080/0022449800955I08I

Marlin, R., Kadakia, A., Ethridge, B., Mathews, W.C. (2018). Physician attitudes toward homosexuality and HIV: The PATHH-III survey. LGBT Health. 5(7),43I-442. doi: I0.1089/ Igbt.2018.004|

McCarthy, J. (June, 2019) Americans still greatly overestimate US gay population. https://news.gallup.com/poll/25957I/ americans-greatly-overestimate-gay-population.aspx

McDonald, J. H. (2014) Handbook of Biological Statistics (3rd ed.). Sparky House Publishing, Baltimore, MD.

McLellan, E., MacQueen, K. M., \& Neidig, J. L. (2003). Beyond the qualitative interview: Data preparation and transcription. Field Methods, 15( I), 63-84.

Meyer, I. H. (2003) Prejudice, social stress, and mental health in lesbian, gay, and bisexual populations: Conceptual issues and research evidence. Psychological Bulletin. 129(5),674697. doi:10.1037/0033-2909.129.5.674

Morris, M., Cooper, R. L., Ramesh, A., Tabatabai, M., Arcury, T. A., Shinn, M., ... \& Matthews-Juarez, P. (2019). Training to reduce LGBTQ-related bias among medical, nursing, and dental students and providers: a systematic review. BMC Medical Education, 19(1), I-13.

Oswalt, S. B., \& Wyatt, T. J. (20II). Sexual orientation and differences in mental health, stress, and academic performance in a national sample of US college students. Journal of Homosexuality, 58(9), 1255-1280.

Patton, M. Q. (1990). Qualitative evaluation and research methods. SAGE Publications, Inc. Newbury Park, CA
Przedworski, J.M., Dovidio, J.F., Hardeman, R.R., et al. (20I5). A comparison of the mental health and well-being of sexual minority and heterosexual first-year medical students: A report from the medical student CHANGE study. Academic Medicine. 90(5), 652-659. doi:10.1097/ ACM.0000000000000658

Qualtrics software, Version 2021 of Qualtrics. Copyright(C) 2021 Qualtrics. Qualtrics and all other Qualtrics product or service names are registered trademarks or trademarks of Qualtrics, Provo, UT, USA. https://www.qualtrics.com

Rankin, S., Blumenfeld, W. J., Weber, G. N., \& Frazer, S. (20I0). State of higher education for LGBT people. Charlotte, NC: Campus Pride.

Rabionet, S. E. (201I). How I learned to design and conduct semi-structured interviews: an ongoing and continuous journey. Qualitative Report, 16(2), 563-566.

Robertson, W.J. (2017). The irrelevance narrative: Queer (in) visibility in medical education and practice: The irrelevance narrative. Medical Anthropology Quarterly. 31(2),159-176. doi: I0.1 III/maq. 12289

Radix, A., \& Maingi, S. (2018, February). LGBT cultural competence and interventions to help oncology nurses and other health care providers. In Seminars in Oncology Nursing (Vol. 34, No. I, pp. 80-89). WB Saunders.

Russell, D., Peplau, L. A., \& Cutrona, C. E. (1980). The revised UCLA Loneliness Scale: concurrent and discriminant validity evidence. Journal of Personality and Social Psychology, 39(3), 472.

Safer J et al. (2016). Barriers to healthcare for Transgender individuals. Current Opinions in Endocrinology \& Diabetes and Obesity. 23(2), I68-171.

Schalet, B. D., Pilkonis, P. A., Yu, L., Dodds, N., Johnston, K. L., Yount, S., ... Cella, D. (2016). Clinical validity of PROMIS Depression, Anxiety, and Anger across diverse clinical samples. Journal of Clinical Epidemiology, 73, 119-127. https://doi.org/10.1016/j.jclinepi.2015.08.036

Seelman, K. L., Colón-Diaz, M. J., LeCroix, R. H., XavierBrier, M., \& Kattari, L. (2017). Transgender noninclusive healthcare and delaying care because of fear: connections to general health and mental health among transgender adults. Transgender Health, 2(I), 17-28.

Strahan, R., \& Gerbasi, K. C. (1972). Short, homogeneous versions of the Marlow Crowne social desirability scale. Journal of clinical psychology, 28(2), 191-193.

Testa, R., Habarth, J., Peta, J., Balsam, K., \& Bockting, W. (2015). Development of the Gender Minority Stress and Resilience Measure. Psychology of Sexual Orientation and Gender Diversity, 2(I), 65-77.

Tetreault, P. A., Fette, R., Meidlinger, P. C., \& Hope, D. (2013). Perceptions of campus climate by sexual minorities. Journal of Homosexuality, 60(7), 947-964.

The Williams Institute, UCLA School of Law. (2020). Adult LGBT Population in the United States. LGBT Demographic 
Data Interactive. Los Angeles, CA. https://williamsinstitute. law.ucla.edu/publications/adult-lgbt-pop-us/

The Williams Institute, UCLA School of Law. (December I, 2019) LGBT Data \& Demographics. https://williamsinstitute. law.ucla.edu/visualization/lgbt-stats/?topic=LGBT\#density

Valandra, V. (20/2). Reflexivity and professional use of self in research: A doctoral student's journey. Journal of Ethnographic \& Qualitative Research, Vol. 6, 204-220 ISSN: 1935-330

White J, Brown A. (202I) Blacks and racism in the dietetics field: From diet related health disparities to racial microaggressions. Critical Dietetics, 6(I), I-3.

White Hughto, J. M., Murchison, G. R., Clark, K., Pachankis, J. E., \& Reisner, S. L. (2016). Geographic and individual differences in healthcare access for US transgender adults: a multilevel analysis. LGBT health, 3(6), 424-433.

Woodford, M.R., Chonody, J.M., Kulick, A., Brennan, D.J., Renn, K. (2015) The LGBQ microaggressions on campus scale: A scale development and validation study. Journal of Homosexuality 62(12), 1660-1687.

Woodford, M. R., \& Kulick, A. (2015). Academic and social integration on campus among sexual minority students: The impacts of psychological and experiential campus climate. American Journal of Community Psychology, 55(I-2), 13-24. 